\title{
EDUCAÇÃO E PESQUISA: CONTRIBUIÇõES TEÓRICO-METODOLÓGICAS DE FREIRE À PEDAGOGIA CRÍTICA
}

\author{
EDUCATION AND RESEARCH: FREIRE'S THEORETICAL METHODOLOGICAL CONTRIBUTIONS TO THE CRITICAL \\ PEDAGOGY
}

\section{EDUCACIÓN E INVESTIGACIÓN: CONTRIBUCIONES TEÓRICO-METODOLÓGICAS DE FREIRE A LA PEDAGOGÍA CRÍTICA}

\author{
ADAMS, Telmo ${ }^{1}$ \\ PEGORARO, Camile ${ }^{2}$
}

\begin{abstract}
RESUMO
O artigo é originário de uma pesquisa bibliográfica que se propõe a retomar a contribuição de Paulo Freire para uma metodologia de educação e pesquisa participativa com o objetivo de indicar elementos para uma pedagogia crítica, a partir da releitura de Pedagogia do Oprimido e Educação como Prática da Liberdade. Em que pese a distância histórica, conclui-se que a busca de pedagogias alternativas críticas encontra, nestas obras, subsídios capazes de potencializar a (re)criação de metodologias de educação popular e pesquisa participativa na América Latina.
\end{abstract}

Palavras-chave: Método Freireano. Educação Popular. Pesquisa Participativa. Pedagogias críticas. América Latina.

\section{ABSTRACT}

The article comes from a bibliographic research that proposes to resume Paulo Freire's contribution to a methodology of education and participatory research aiming to indicate elements for a critical pedagogy, based on the rereading of Pedagogy of the Oppressed and Education as a Practice of Freedom. Despite the historical distance, it is concluded that the search for critical alternative pedagogies finds, in these works, subsidies capable of enhancing the (re)creation of methodologies of popular education and participatory research in Latin America.

Keywords: Freire's Method. Popular Education. Participatory Research. Critical pedagogies. Latin America.

\section{RESUMEN}

El artículo se origina en una investigación bibliográfica que se propone a retomar la contribución de Paulo Freire para una metodología de educación e investigación participativa, con el objetivo de indicar elementos para una pedagogía crítica, basada en la relectura de la Pedagogía del Oprimido y Educación como Práctica de la Libertad. A pesar de la distancia histórica, se concluye que la búsqueda de pedagogías alternativas críticas encuentra, en estas obras, subsidios capaces de potencializar la (re)creación de metodologías de educación popular e investigación participativa en América Latina.

Palabras clave: Método Freireano. Educación popular. Investigación participativa. Pedagogías críticas. América Latina.

\footnotetext{
${ }^{1}$ Universidade do Vale do Rio dos Sinos - Unisinos - Brasil.

${ }^{2}$ Universidade do Vale do Rio dos Sinos - Unisinos - Brasil.
} 


\section{INTRODUÇÃO}

De acordo com diversos autores como Giroux (1997), as pedagogias críticas podem ser reconhecidas pela problematização e prática interrogante das múltiplas formas de relações de subordinação ou dominação. Para este autor, a pedagogia crítica se constitui em uma política de vida na qual "[...] educadores e estudantes estão comprometidos no trabalho da história; como tal trata-se de uma pedagogia que faz a mediação com as relações concretas entre os indivíduos e a cultura e as formas institucionais, a qual desperta a um compromisso social" (GIROUX, 1997, p. 225 - tradução nossa).

As pedagogias críticas partem da interpretação do contexto, em vista de fornecer mediações teóricas e metodológicas que contribuam para desenhar estratégias ético-políticas e subsidiar práticas sociais fortalecedoras de processos de transformação social, desde as realidades concretas dos sujeitos que anseiam por libertação. Nesse sentido, uma pedagogia pode ser considerada crítica quando é produtora de conhecimento no processo de constituição de sujeitos políticos, envolvendo questões como justiça, responsabilidade, democracia, lutas contra as desigualdades.

$\mathrm{Na}$ América Latina, existe uma variedade de denominações para pedagogias críticas que reflete as práticas educativas em diversos contextos e tempos. Pelo fato de nos referirmos, especialmente, a duas obras de Freire, utilizaremos mais a sua terminologia: pedagogia do oprimido, pedagogia libertadora. Porém, com a contribuição desse autor, criaram-se as diversas expressões de educação popular, como um dos destaques das pedagogias críticas, com diversas denominações, entre as quais destacamos a do Programa Alternativas Pedagógicas e Prospectivas Educativas para América Latina - APPEAL.

Com o protagonismo de Adriana Puiggrós junto à Faculdade de Filosofia e Letras da UNAM, no período do seu exílio a partir de 1985, surgiu a APPEAL, hoje presente em diversos países latinoamericanos. A partir de uma crítica às concepções dicotômicas e maniqueístas - entre as quais, certas correntes da educação popular, com a divisão da sociedade entre opressores e oprimidos - a APPEAL ampliou a concepção para a ideia de "alternativas pedagógicas". De acordo com Mercedes Rodríguez (2013), esta ampliação conceitual apresenta uma graduação de alternatividade de acordo com o nível de ruptura com os sistemas dominantes. A alternativa estaria na ordem da afirmação, oferecendo uma perspectiva de busca do elemento potencial a ser ativado em certo horizonte de sentido: um projeto transformador construído coletivamente na busca do ser mais.

$\mathrm{Na}$ mesma linha, temos também denominações diversas para a pesquisa: investigação temática, investigação ação participativa, pesquisa participante, pesquisa ação, investigação desde as margens, entre outras (STRECK e ADAMS, 2019). O que se pode destacar de comum entre todas as modalidades é a postura epistêmica descolonial e opção ético-política e "que permite ver, dizer e fazer o que não é visível, nomeável ou factível desde o centro das instituições de conhecimento e poder" (TORRES, p. 66 - tradução nossa).

Em perspectiva semelhante, Ortega Valencia (2018) amplia a compreensão das pedagogias críticas afirmando que 
A pedagogia crítica possibilita-nos visibilizar e denunciar as condições estruturais da desigualdade em todos os sujeitos na e desde a luta por construir modos de vida mais justos democráticos e solidários em todos os âmbitos (econômicos, políticos, culturais, educativos e subjetivos) e, de igual modo, compromete-se com a potencialização de sujeitos na e desde a luta para construir modos de vida mais justos, democráticos e solidários. (ORTEGA, 2018, p. 128 tradução nossa).

Com base nessa concepção, a autora destaca que as pedagogias críticas apresentam características como: a) uma ação político-pedagógica voltada às lutas de resistência, de defesa e afirmação dos direitos humanos; b) o ampliação da consciência, posição crítica e transformadora dos sujeitos envolvidos nas ações coletivas; c) o reconhecimento, denúncia e incidência em assuntos vitais "como a constituição da educação como direito público, a valorização dos profissionais da educação" (ORTEGA, 2019, p. 133 - tradução nossa); d) a problematização dos contextos de desigualdade e suas dinâmicas de exclusão e violências; e) e, por fim, a emergência de práticas políticas protagonizadas pelos sujeitos empobrecidos.

As pedagogias críticas e a pesquisa participativa constituem-se de alguns elementos fundantes, expressos com maior profundidade nos livros Educação como Prática da Liberdade e Pedagogia do Oprimido. Trazemos, neste texto, reflexões sobre alguns fundamentos que consideramos significativos e com potencial transformador: a educação com finalidade de superação da contradição opressores e oprimidos; a dialogicidade que implica na consciência da inconclusão e na busca pelo ser mais; e a importância do conteúdo programático. Finalmente, damos ênfase à elucidação de um método freireano de educação e pesquisa que continua a ser frutífero na (re)criação de pedagogias críticas alternativas e na pesquisa participativa.

\section{EDUCAÇÃO LIBERTADORA PARA A SUPERAÇÃO DA CONTRADIÇÃO OPRESSORES E OPRIMIDOS}

A educação libertadora proposta por Freire se constitui em uma das vertentes da pedagogia crítica na América Latina, na medida em que seu pensamento parte das condições de discriminação, violências, e desigualdades sociais "que faz com que a reflexão teórica seja indispensável e, por sua vez, a transformação da realidade por meio da práxis entendida como ação para a transformação" (ORTEGA, 2018, p. 121 - tradução nossa). A educação crítica não ocorre na palavra sem reflexão, mas sim na autenticidade da ação educativa que se constitui, em sua essência, no anseio dos seres humanos em descobrirem o pouco que sabem de si mesmos, e, assim, problematizarem-se por meio do diálogo. $\mathrm{Na}$ inquietação por saberem mais de si mesmos, questionam, respondem e, dessas respostas emergem novas perguntas.

A contradição entre opressores e oprimidos ocorre na relação dialética entre desumanização e humanização, esta última negada no processo de opressão, injustiça e violência dos opressores que leva os oprimidos a ser menos. A educação crítica oportuniza a auto percepção de sua desumanização e tem como objetivo a busca pela humanização retirada pela brutalidade do sistema de acumulação. 
$\mathrm{Na}$ ordem opressora, os seres humanos são coisificados, reduzidos a mercadoria, para estarem à disposição do propósito dos opressores: a produção e acumulação cada vez maior de capital.A pedagogia freiriana pauta-se pelo desafio ético-político expresso na necessidade de superação dessa situação, o que implica em conhecer criticamente as razões da realidade vivida. A ação transformadora, ao incidir sobre a realidade objetiva, implica a luta pela superação desta, viabilizando a educação para o ser mais.

A viabilidade desta finalidade da educação esbarra no fato de que as oprimidas e os oprimidos, imersos na estrutura social de dominação, "temem a liberdade, enquanto não se sentem capazes de correr o risco de assumi-la" (FREIRE, 2011, p. 47). Por isso, Freire identifica a libertação como um processo doloroso a ser desempenhado pelos que sofrem com a sua ausência, e que, somente na superação das contradições, podem produzir um novo ser: ao compreenderem o antagonismo das relações opressoras entre eles, gradativamente, assumem a liberdade e empenham-se coletivamente no processo transformador da situação opressora na sua totalidade ${ }^{3}$ e não apenas na dimensão individual.

A transformação objetiva implica a modificação da subjetividade, distinta do subjetivismo estático que espera passivamente o desaparecimento da opressão. Porque subjetividade e objetividade, implicadas em uma relação dialética, não podem ser contraditórias, mas compõem uma totalidade. Aqui, a educação é chamada a cumprir seu papel que, quando limitado aos condicionamentos da sociedade de capital, é de resistência e proposição.

A realidade social objetiva só existe como produto da ação humana e, portanto, só se transforma quando há consciência social da necessária libertação. A imersão na realidade opressora é mecanismo de absorção de todos que nela se encontram. Esta alienação das consciências só pode ser superada na e pela práxis que, na compreensão de Freire (2011, p. 52), assume o compromisso da ação humana sobre o mundo para sua transformação. A práxis se dá pela "inserção crítica dos oprimidos na realidade opressora, com que, objetivando-a, simultaneamente atuam sobre ela" (FREIRE, 2011, p. 53). Este é um fundamento essencial da educação libertadora bem como da pesquisa participativa: esta pesquisa, que não se realiza por meio de uma simples busca de dados, mas objetiva a inserção e reconhecimento dos oprimidos da situação problema em que se encontram. O reconhecimento de uma realidade que não leva à inserção crítica nela, não pode ser considerado verdadeiro.

Freire alerta que é do interesse das classes dominantes manter apenas o estado de imersão, para impedir a transposição da situação limite à que as classes dominadas se encontram condicionadas. Em decorrência, a pesquisa participativa encontra seus fundamentos e objetivos no fato de que, quanto mais a realidade é desvelada, maior é a possibilidade de inserção dentro desta. Dialeticamente, convergem pensamento, objetividade-subjetividade e diálogo, mediatizados pelo mundo, isto é, pela ação no mundo. O diálogo implica compreender que a inserção das massas na

\footnotetext{
${ }^{3}$ A categoria totalidade tem, aqui, o sentido marxiano, de totalidade das relações sociais estabelecidas em determinada sociedade, sob determinado meio de produção da vida. Transformar a situação opressora, portanto, diz respeito à transformação global de uma sociedade, atingindo todos os âmbitos da vida. Nos sentidos econômicos e sociais; objetivos e subjetivos.
} 
realidade por meio da práxis é condição para a transformação social. A pedagogia crítica freiriana baseia-se na realidade e no potencial humanizador dos oprimidos como exemplos para si mesmos e busca a restauração da sua subjetividade na relação com a objetividade.

Cada sociedade produz o modelo de educação necessário à sua reprodução, de acordo com o projeto hegemônico. O modelo dominante visa à manutenção do seu status quo que, inevitavelmente, estará em choque com outros modelos que buscam hegemonizar-se, como a educação libertadora. Aqui se faz necessária a "distinção entre educação sistemática, a que só pode ser mudada com o poder, e os trabalhos educativos, que devem ser realizados com os oprimidos, no processo de sua organização" (FREIRE, 2011, p. 57). Enquanto estivermos imersos na situação opressora, à pedagogia-pesquisa crítica cabe o trabalho educativo para a organização das "massas" oprimidas. Mesmo sabendo que a educação, sozinha, não transforma, Freire conclui que tampouco sem ela será possível a transformação social.

Esta pedagogia do oprimido e não para o oprimido se compõe de dois momentos que são centrais no pensamento freireano:

O primeiro, em que os oprimidos vão desvelando o mundo da opressão e vão comprometendose, na práxis, com a sua transformação; o segundo, em que, transformada a realidade opressora, esta pedagogia deixa de ser do oprimido e passa a ser a pedagogia dos homens [ $\mathrm{sic}$ ] em processo de permanente libertação. (FREIRE, 2011, p. 57).

Nesta escrita de Freire, podemos deduzir que sua concepção não era dicotômica, senão que tinha uma clara visão de classes ampliada por toda a massa da população que não era considerada uma classe produtora de mercadorias na lógica da exploração direta pelo capital. Para ele, superada a realidade opressora, a pedagogia do oprimido deixaria de existir. Como a opressão não acabou até o momento, esta pedagogia continua com seu potencial de contribuir no processo de libertação. A contribuição ocorre na educação para a autonomia, para a solidariedade, para o envolvimento em práticas libertadoras locais e participação em lutas mais amplas por uma sociedade na qual todas e todos tenham condições iguais para serem gente realizada, solidária e feliz.

Para realizar esse primeiro movimento de conscientização em torno das contradições vividas no cotidiano, exige-se das educadoras e educadores uma visão nítida da cultura da dominação por meio da percepção do mundo opressor e pela desmistificação da estrutura opressora, geradora da violência. É necessário compreender que a própria existência dos oprimidos pressupõe a violência da opressão materializada na concentração dos bens da natureza e dos produtos do trabalho humano, em que uma minoria economicamente privilegiada nega os direitos humanos à maioria. A transformação que se conquista na primeira fase da pedagogia do oprimido não será algo mágico, sem conflitos que, inclusive, pode passar pela rebelião dos oprimidos como resposta à violência sofrida. Contudo, "o ato de rebelião dos oprimidos, que é sempre tão ou quase tão violento quanto a violência que os cria, este ato dos oprimidos, sim, pode inaugurar o amor", porque a busca dos oprimidos é pelo direito de ser mais (FREIRE, 2011, p. 59). 
Deste modo, Paulo Freire propõe uma educação comprometida, crítica e transformadora que se constitui instrumento para a libertação do sistema de opressão estabelecido, como processo permanente de educação para a autonomia e o enfrentamento da cultura opressora incorporada nos indivíduos e nas relações sociais em geral.

\section{EDUCAÇÃO DIALÓGICA PARA A CONSCIÊNCIA DA INCONCLUSÃO EM BUSCA DO SER MAIS}

Para cumprir seu papel na tarefa histórica dos oprimidos e oprimidas, a educação precisa criar seus alicerces na ação cultural. Esta compreende conhecer a opressão, reconhecer a imersão neste regime e a organização da luta para combatê-lo. Em consequência, contribui no cumprimento da tarefa histórica libertadora. Essa tarefa realiza-se na práxis, mediada pelo diálogo, pelo reconhecimento do outro, cujo processo vai além da comunicação. Dialogar é mais do que comunicar. Para Freire, comunicar implica informar, em uma via única; enquanto o diálogo pressupõe a troca e a construção coletivas com sintonia de concepções e intencionalidades. Ao substituir o diálogo pela comunicação na prática educativa, os indivíduos correm o risco de utilizarem-se de instrumentos dos opressores, o que não leva à libertação, mas a um novo sistema de domesticação. A libertação necessita da reflexão dialogada que conduz à prática, porque ação e reflexão constituem a práxis e não devem ser dicotomizadas. Quando a educadora e o educador creem no potencial libertador dos oprimidos e oprimidas, contribuem para que eles e elas se considerem capazes de pensar e construir o mundo.

A educação na perspectiva libertadora e a democratização da educação têm uma contribuição fundamental para desmistificar a meritocracia, quando desmantelam as narrativas históricas que colocam os oprimidos em situação de subserviência intelectual e social. Este processo leva sujeitos historicamente segregados a questionar o discurso da elite dominante, seus valores e o comportamento esperado das pessoas e grupos dominados.

A ação cultural se desenvolve também por meio do diálogo entre lideranças e a massa oprimida e não pela propaganda sloganizada que significa depósito de informações de lideranças para as massas, modelo historicamente usado pelos opressores. Quando oprimidas e oprimidos reconhecem a vulnerabilidade da sua dependência e tentam, mediante a reflexão e a ação, subverter essa dependência, criam seu oposto dialético. Assim, não incorrem no risco de usar, na pretendida libertação, o mesmo procedimento usado para a opressão. Deste modo, Freire apresenta o caráter pedagógico como construção coletiva, não como propaganda colonizadora, em que o pretenso libertador impõe ao oprimido sua forma de entender a libertação. Nesta prática, o método deixa de ser instrumento de manipulação para tornar-se um itinerário de conscientização que implica engajamento para mudar a realidade que oprime. Isso porque "[...] a consciência é, em sua essência, um "caminho para' algo que não é ela, que está fora dela, que a circunda e que ela apreende por sua capacidade ideativa. Por definição, a consciência é, pois, método, entendido esse no seu sentido de máxima generalidade" (FREIRE, 2011, p. 77). Nesta citação, evidencia-se a diferença entre pseudoparticipação e engajamento. Podemos identificar uma relação direta entre concepção bancária: comunicação como transmissão de informações, pseudoparticipação, ideologização ou alienação; de outro lado, a pedagogia dialógica crítica, problematizadora que integra a ação cultural: o diálogo, o 
engajamento que se constitui na conscientização como práxis libertadora. A ação cultural incide sobre a unidade de educadoras e educadores, educandas e educandos para a libertação, distinguindo-se radicalmente da concepção bancária de educação.

Pedagogicamente, a ação cultural tem como ponto de partida a investigação temática, que diz respeito à conscientização de todas e todos independentemente de sua tarefa a cumprir no processo de transformação. Ela prioriza a compreensão da cultura como superestrutura e importância de transformá-la. Constitui-se, não somente um método pedagógico de ensino, mas práxis dialógica que se prolonga em revolução cultural. Nessa ação dialógica, educadoras e educadores, educandas e educandos dos grupos oprimidos conhecem o porquê e o como aderem à realidade em cuja relação acabam tendo um conhecimento falso de si mesmos e da própria realidade.

A práxis dialógica se opõe à ideologia enquanto distorção da realidade, segundo os interesses da classe dominante. Desvenda as formas de opressão para avançar na compreensão que toda cultura estará, consciente ou inconscientemente, sempre a serviço da dominação ou da libertação em cada estrutura social. A ação cultural, portanto, constrói conhecimento com o povo, não transmite ou entrega algo pronto. Constrói em conjunto, em uma interação não-colonizadora. Nessa prática não há atores e espectadores, pois todas e todos são sujeitos do processo de ação histórica na superação da cultura alienante.

$\mathrm{Na}$ concepção bancária ou antidialógica de educação, ao contrário, as relações entre educadoras e educadores, educandos e educandas são narradoras e dissertadoras, pautadas na recepção/memorização mecânica de conteúdos estáticos. Essa concepção educativa disserta sobre questões alheias às experiências materiais, conteúdos desconexos, recortados da realidade na qual ganham significação fragmentada. Nesse modelo hierárquico, a educação estabelece uma dicotomia em que alguns detém todo o conhecimento, enquanto a maioria é tida como ignorante. Aqui a educação é "o ato de depositar, de transferir, de transmitir valores e conhecimentos" (FREIRE, 2011, p. 80), que fortalece a contradição entre quem educa e quem aprende. Na visão bancária de educação, a ignorância está com as pessoas que possuem menor poder no processo. Desse modo, esta fortalece o modelo de sociedade e os interesses do opressor, enquanto anula o poder criador das oprimidas e oprimidos.

A pedagogia antidialógica é o meio pelo qual os opressores pretendem adaptar as mentalidades para aceitação da situação opressora e facilitar a dominação. Todavia, esse sistema educativo carrega as suas contradições e é nele que se encontram, também, as condições necessárias para superá-lo.

Da superação das contradições deverá emergir a educação problematizadora, caracterizada pela relação horizontal entre agentes deste processo em que todas e todos aprendem e ensinam. Homens e mulheres "se educam em comunhão, mediatizados pelo mundo" (FREIRE, 2011, p. 96). Na problematização há criação de situações para superar o conhecimento como crença ingênua e alcançar um nível de conhecimento ativo, de engajamento solidário em vista de transformar a realidade na qual estão inseridos. Isso implica um constante ato de desvelamento da realidade, no sentido de ver o que está por trás ou no interior dos fenômenos e suas interconexões com a realidade mais ampla. 0 ato de conhecer a essência dos fenômenos é a base da educação como prática de liberdade "[...] 
implica a negação do homem abstrato, isolado, solto, desligado do mundo, assim como também a negação do mundo como uma realidade ausente dos homens" (FREIRE, 2011, p. 98).

$\mathrm{Na}$ visão de Freire, consciência e mundo são simultâneos. Em consequência, a reflexão autêntica da educação libertadora não é sobre o mundo, mas sim sobre as relações com o mundo. Este não se constitui na ausência do ser humano, porque há a necessidade da consciência sobre o mundo para que este exista. Só existe mundo porque a consciência humana assim o nomeou, ao mesmo tempo em que o mundo, na sua materialidade, é anterior à consciência deste. Desse modo, compreender o mundo, desmistificar sua existência é devir histórico da educação libertadora. Enquanto na educação bancária os conteúdos estão prontos para serem depositados, na prática educativa problematizadora os educandos e educandas desenvolvem sua captação e compreensão do mundo em constante movimento de transformação.

Da mesma forma, na pesquisa participativa ocorre a problematização e construção em conjunto com os sujeitos envolvidos. Não há dicotomia entre pesquisadora/es e pesquisadas/os. Há a sistematização, em diálogo com os participantes, potencializando o conhecimento já existente entre o grupo pesquisado. Educação e pesquisa acontecem por meio do diálogo criador, baseado em um profundo amor ${ }^{4}$ ao mundo. Só assim pode expressar-se como pronúncia do mundo e como ato dialógico, que só pode acontecer com base na humildade e não na arrogância.

O diálogo ocorre no reconhecimento de que a solidariedade é possível nas relações, em oposição à propriedade da verdade, à ideia de que a pronúncia do mundo é tarefa de homens seletos, contrária à presença das massas no fazer histórico. Esta é uma das bases do pensamento crítico latino-americano: a articulação da criticidade com dialogicidade. Sem o pensar crítico não há diálogo, tampouco verdadeira educação. Como já afirmamos, a educação libertadora não parte da ideia de levar às educandas e aos educandos um modelo de ser humano, mas que mulheres e homens devem construir-se coletivamente no processo educativo.

Atuar sobre e para as pessoas consiste em doutrinação para adaptá-las às condições de dada realidade que os dominadores querem que permaneça intocável e inquestionável. A dominação das consciências pela elite se dá na ação apassivadora em que o oprimido recebe conteúdos que ensinam a temer a liberdade, que o levam ao mutismo, ao sentimento de inferioridade, à impotência e à desesperança. Ao invés de o oprimido ser respeitado na sua visão de mundo e na sua cultura, a educação bancária significa "[...] uma espécie de invasão cultural, ainda que feita com a melhor das intenções" (FREIRE, 2011, p. 119).

Em síntese, enquanto a prática bancária desconhece a historicidade humana, a pedagogia problematizadora percebe os seres humanos como inacabados, inconclusos, inseridos em uma realidade histórica também inacabada. Na consciência da sua inconclusão encontram as raízes da educação libertadora.

Nesta perspectiva, os humanos se identificam como "seres que caminham para a frente; como seres a quem o imobilismo ameaça de morte; para quem o olhar para trás não deve ser uma forma nostálgica de querer voltar, mas um modo de melhor conhecer o que está sendo, para melhor construir

\footnotetext{
${ }^{4}$ Amor é o fundamento do diálogo e o compromisso com a causa dos oprimidos. (FREIRE, 2011).
} 
o futuro" (FREIRE, 2011, p. 103). Em vez de enfatizar a visão fatalista, a prática problematizadora "propõe aos homens [sic] sua situação como problema" (FREIRE, 2011, p. 103), o que permite enxergar a realidade e a si mesmos como transformáveis. A realidade objetificada é resultado da ação humana e, portanto, pode ser modificada.

Ao contrário da prática bancária que, no máximo, pretende amenizar as desigualdades, a concepção problematizadora evidencia as contradições propondo a luta emancipatória por meio do diálogo, fundamento do conteúdo programático da educação. A isto deve-se a importância de que este não seja previamente elaborado para ser doado, e sim que se constitua na "devolução organizada, sistematizada e acrescentada ao povo daqueles elementos que este lhe entregou de forma desestruturada" (FREIRE, 2011, p. 116). É desta questão que trataremos a seguir.

\section{CONTEÚDO PROGRAMÁTICO DA EDUCAÇÃO E BASES PARA A PESQUISA PARTICIPATIVA}

É a partir da situação humana no mundo, das suas aspirações, que se organiza o conteúdo programático da educação. Tanto na educação como na pesquisa, o tema proposto foca-se na situação existencial concreta do povo, aquele que "o desafia e, assim, lhe exige resposta, não só no nível intelectual, mas no nível da ação" (FREIRE, 2011, p. 120). Não na forma de imposição de conteúdos, mas na relação dialógica por meio da qual o educador-pesquisador e a educadorapesquisadora entram em sintonia para conhecer o campo empírico. Estes ouvem as pessoas com alguma convivência dialógica e observação, buscam levantar aspectos relevantes, com atenção especial para os conflitos e contradições vividas na coletividade. Deste processo serão definidos os temas geradores, sempre em diálogo com os participantes.

O momento de busca do "conteúdo programático" da educação "inaugura o diálogo da educação como prática da liberdade. É o momento em que se realiza a investigação do que chamamos de universo temático do povo ${ }^{5}$ ou o conjunto de seus temas geradores" (FREIRE, 2011, p. 121). Esta investigação implica uma metodologia que não contradiga a dialogicidade, proporcionando, tanto a apreensão dos temas geradores, quanto a tomada de consciência. Por isso, os participantes são sujeitos e não objetos da investigação. Trata-se de estudar o pensamento-linguagem, os níveis de percepção e a visão de mundo em que se encontram envolvidos os temas geradores.

É como seres transformadores e criadores que mulheres e homens transformam, não somente o mundo cultural, mas, em conjunto, suas concepções sobre o mundo. Assim, criam história, ao mesmo tempo em que se fazem seres históricos. Um tempo histórico caracteriza-se pelo "conjunto de ideias, de concepções, esperanças, dúvidas, valores, desafios, em interação dialética com seus contrários, buscando plenitude" (FREIRE, 2011, p. 128). A representação concreta do conjunto destas características, que são temas em interação, constitui "o universo temático da época" (FREIRE, 2011, p. 129), que mais do que características, são tarefas a serem cumpridas. Cada ser humano, numa relação contraditória e dialética, realiza tarefas em favor da transformação ou da manutenção das estruturas.

\footnotetext{
${ }^{5}$ Povo conota aqui um sentido genérico que na prática se refere aos sujeitos participantes, sejam grupos, comunidades ou organizações com quem se realiza o processo educativo ou de pesquisa.
} 
A compreensão do universo temático tem profunda relação com a pesquisa em educação. Nesta perspectiva, os objetivos que pesquisadora e pesquisador levam ao campo empírico precisam ser o mais abertos possíveis, para que os sujeitos da pesquisa possam contribuir verdadeiramente com os seus saberes e compreensões sobre o seu tempo histórico. Isto porque a percepção destas tarefas, deste universo temático de cada época, implica a percepção do inédito viável. À pesquisa em educação e à educação libertadora cabe contribuir para a superação das situações-limites e inéditos viáveis de nosso tempo: a conquista dos direitos humanos na sua plenitude, a radicalidade democrática e, com ela, a soberania do Estado Democrático de Direito.

Com base nesses fundamentos, encontramos na Pedagogia do Oprimido, um itinerário de pesquisa que continua inspirador, tanto da educação popular, como da pesquisa participativa.

\section{INDICATIVOS DE UM MÉTODO DE PESQUISA NO PEDAGOGIA DO OPRIMIDO}

Entre os fundamentos teórico-epistemológicos de Freire que apresentamos até o momento destacamos alguns aspectos centrais para a compreensão de seu Método de educação e pesquisa.

Uma de suas concepções fundantes encontra-se na diferença entre seres humanos e animais, com base em Karl Marx: os humanos como únicos seres inconclusos "capazes de ter, não apenas sua própria atividade, mas a si mesmos, como objeto de sua consciência, o que os distingue do animal, incapaz de separar-se de sua atividade" (FREIRE, 2011, p. 122). Sua existência é histórica pelo fato de terem consciência da sua atividade e do mundo em que estão. Ao atuarem, o fazem com alguma intencionalidade que eles mesmos propõem. Impregnam o mundo de sua presença criadora, fazendo com que o espaço físico também se torne histórico. Nas suas relações com os outros e com o mundo que objetivam, separando-se dele, criam as condições para ultrapassar as situações-limites. Estas não são barreiras insuperáveis, mas dimensões desafiadoras da realidade concreta e histórica sobre as quais os sujeitos incidem com suas ações para superá-las e negá-las (FREIRE, 2011).

Quando nas relações homem-mundo se instaura a percepção crítica dessa situação, desenvolve-se o clima de esperança para a superação. E superadas estas, aparecerão novas situações-limites que exigirão outras respostas transformadoras. Portanto, o que limita e leva à aceitação dócil e passiva não é a situação-limite em si, mas a percepção que homens e mulheres têm dela em determinado tempo histórico. Por meio da práxis humana sobre o mundo, criam o domínio da história e da cultura. Esta práxis, "sendo reflexão e ação verdadeiramente transformadora da realidade, é fonte de conhecimento reflexivo e criação" (FREIRE, 2011, p. 127). Por esse motivo, a educação não pode ser verdadeira se não for processo de apropriação de conceitos, conhecimentos para que o sujeito se aproprie deles e consiga analisar as situações-limites do seu tempo histórico. Assim, ele poderá buscar a transposição dessas situações na sua prática diária, no diálogo e na cooperação com outros sujeitos.

Freire reafirma, na sua concepção epistemológica, a unidade dialética entre objetividade e subjetividade, juntamente com a dimensão ético-político da pesquisa: conhecer a realidade na sua contradição entre opressores e oprimidos, para transformá-la. Tal ensejo, implica superar a mitificação para assumir um processo de crítica radical permanente em relação aos processos sociais de 
desigualdade e injustiças sociais. Implica, da mesma maneira, a luta por uma sociedade justa, solidária onde todas e todos possam viver humanamente, com igualdade de condições e acesso aos bens da natureza e aos socialmente produzidos. A pesquisa e a educação, como afirmado anteriormente, não são processos isolados, mas conexões entre pesquisadoras/es e sujeitos do campo empírico em busca da ampliação das consciências de ambos (ADAMS et al, 2017).

O que é Método de investigação e educação para Freire? O autor compreende educação e pesquisa de modo articulado, como permanente esforço de reflexão dos oprimidos sobre suas condições concretas, ação essa com eles e não para eles (FREIRE, 2011). Apresenta, assim, princípios básicos da pesquisa participativa, cujo método propõe: a) sua (re)construção a partir dos sujeitos da investigação; b) a dimensão pedagógica da investigação, sendo parte intrínseca, como afirma com muita clareza: "[...] toda investigação temática de caráter conscientizador se faz pedagógica e toda autêntica educação se faz investigação do pensar" (2011, p.142); c) a realidade social como movimento, onde criamos história e fazemo-nos seres histórico-sociais; e d) o educar e o investigar são, essencialmente, interdisciplinares por estarem inseridos na realidade concreta.

\footnotetext{
Tanto quanto a educação, a investigação que a ela serve, tem de ser uma operação simpática, no sentido etimológico da expressão. Isto é, tem de constituir-se na comunicação, no sentir comum uma realidade que não pode ser vista mecanicistamente compartimentada, simplistamente bem "comportada", mas, na complexidade de seu permanente vir a ser. Investigadores profissionais e povo, nesta operação simpática, [...] são ambos sujeitos deste processo. (FREIRE, 2011, p. 140).
}

Ao propor um itinerário para a investigação do universo temático e temas geradores, Freire (2011) aponta alguns passos do seu método em que propõe no contexto de um trabalho coletivo. Devido à não separação entre pesquisadoras, pesquisadores e sujeitos de pesquisa, Freire indica, como primeiro passo, a aproximação. Sugere um encontro informal de diálogo para explicitar os objetivos de sua presença na comunidade ou organização com quem pretende propor a pesquisa participativa. Nessa conversa informal "dirão o porquê, o como e para que da investigação que pretendem realizar e que não podem fazê-lo se não se estabelece uma relação de simpatia e confiança mútuas" (FREIRE, 2011, p. 144).

Na sequência, em caso de aceitarem e aderirem, à educadora-pesquisadora e ao educadorpesquisador cabe estimular um grupo que queira participar diretamente do processo de investigação envolvendo algumas pessoas para serem colaboradoras com "postura ativa na investigação". (FREIRE, 2011, p. 137) Após uma preparação básica em torno de princípios da educação popular e da pesquisa participativa, segue um segundo passo: a realização de visitas de observação com atitude compreensiva em face do que se observa, cuidando para "os investigadores não imporem seu marco valorativo [...]" (FREIRE, 2011, p. 122), pois o método genuíno de aproximação não se impõe.

A partir do que se levanta na realidade, com o máximo de registros em caderno de campo, segue o passo da codificação resultante da observação dos fatos e da conversação informal. Importa destacar, das informações levantadas, a maneira de conversar, sua forma de ser, seu comportamento no culto religioso, no trabalho; enfim, registrar as diferentes expressões como a linguagem, as 
palavras, a pronúncia, o como constroem o pensamento e assim por diante. Na observação participante, que exige um nível de convivência, Freire sugere ampliar as visitas às pessoas nas suas casas, nas reuniões e atividades diversas com atenção às relações que estabelecem, ao papel das mulheres e jovens, às formas de lazer ou atividades esportivas; observar, por exemplo, as relações entre marido e mulher, pais e filhos, etc.

Um quarto passo tem a ver com a elaboração de um relatório ou sistematização, preparando o conteúdo e dinâmica para realizar o diálogo da equipe com a comunidade (sujeitos do campo empírico). Esse momento pode ampliar-se com várias outras rodas de conversa para problematizar e aprofundar coletivamente a compreensão sobre os aspectos mais importantes do levantamento realizado até então. A culminância desse passo pode ser a realização de um seminário no processo de descodificação que avalia os achados dos quais educadores-pesquisadores e participantes vão se apropriando, fazendo a reflexão crítica e levantando possibilidades de superação das principais 'situações-limites'.

\footnotetext{
No momento, 're-admiram' sua admiração anterior no relato da 'ad-miração' dos demais. Desta forma, a "cisão" que fez cada um da realidade, no processo particular de sua descodificação, os remete, dialogicamente, ao todo "cindido" que se retotaliza e se oferece aos investigadores a uma nova análise, à qual se seguirá novo seminário avaliativo e crítico, de que participarão, como membros da equipe investigadora, os representantes populares. (FREIRE, 2011, p. 147).
}

Em meio a essa dinâmica, que não ocorre de modo linear, acontece a pontualização do conjunto das contradições como 'situações-limites' sempre em equipe. De acordo com as prioridades estabelecidas no processo, em termos de foco da investigação, podem ser escolhidas algumas situações "com que serão elaboradas as codificações que vão servir à investigação temática" (FREIRE, 2011, p. 150).

A interpretação dá continuidade à problematização que leva à compreensão crítica da realidade. Nessa dinâmica, ocorre a produção de conhecimento com aprofundamento teórico, para subsidiar o que é possível fazer coletivamente em vista do processo de transformação. Esse é o momento privilegiado da educação em que se oportuniza a apropriação crítica pelos sujeitos - grupos, comunidade - e a consequente práxis transformadora. Trata-se de um caminho exigente para que os oprimidos compreendam o fenômeno da introjeção do opressor. Nas palavras de Freire (1992, p. 106): "Só no entendimento dialético, repitamos, de como se dão consciência e mundo, é possível compreender o fenômeno de introjeção do opressor pelo oprimido, a aderência desde àquele, a dificuldade que tem o oprimido de localizar o opressor fora de si, oprimido".

Freire aponta um último passo em que pesquisadores/as avançam na escrita do relatório final de pesquisa - a sistematização da caminhada que continua - e propõe aportes de compreensão teórica para ampliar permanentemente a conscientização crítica para que os oprimidos possam cada vez mais "dizer a sua palavra" e deixem de culpar-se pela situação em que se encontram. Neste aspecto, como em vários outros, Freire valoriza Álvaro Vieira Pinto (1981, p. 21-22), conforme o cita em Ação cultural para a liberdade: 
Problematizar a palavra que veio do povo significa problematizar a temática a ela referida, o que envolve necessariamente a análise da realidade, que se vai desvelando com a superação do conhecimento puramente sensível dos fatos pela razão de ser os mesmos. Assim, e pouco a pouco, os alfabetizandos vão percebendo que o fato de, como seres humanos, falarem, não significa ainda que dizem a sua palavra. É necessário, na verdade, reconhecer que o analfabetismo não é em si um freio original. [...] Ninguém é analfabeto por eleição, mas como consequência das condições objetivas em que se encontra.

Enfim, com cada passo da pesquisa ocorre também o processo educativo. E cabe aos pesquisadores/as a elaboração da síntese que Freire identifica como resultado da pesquisa. Em outras palavras, significa "incorporar-se ao povo na aspiração reivindicativa. De outro, problematizar o significado da própria reivindicação" (FREIRE,2011. p. 251) problematizando a situação histórica, real, concreta.

\section{CONSIDERAÇÕES FINAIS}

As pedagogias críticas na América Latina apresentam um amplo leque de maneiras e arranjos teórico-epistemológicos; e, consequentemente, também as metodologias de pesquisa, nelas inspiradas ou ancoradas, apresentam um elevado grau de diversidade. Em que pesem essas variações, educação popular, alternativas pedagógicas ou os distintos modos de pesquisas participativas continuam a ver em Paulo Freire um dos seus autores de referência. Centralmente, todas as pedagogias e metodologias focam na crítica aos modelos educativos e de sociedade dominantes e se constituem numa alternativa que contempla uma denúncia ao sistema hegemônico e proposição de alternativas com conteúdo ideológico, ético-político; alternativas estas sempre inacabadas e em reconstrução.

A contribuição de Paulo Freire para o campo das pedagogias críticas em contextos de reascensão de governos de extrema-direita aparece como um dos aportes mais atuais. Especialmente, em tempos em que forças antidemocráticas de inspiração fascista tendem a ampliar a dominação em todos os âmbitos da vida individual e social. Neste contexto, o método desenvolvido por Paulo Freire, por meio de suas práticas questionadoras da realidade, tem muito a contribuir para o desenvolvimento de seres capazes de interpretar o momento histórico em que vivem. Como nos ensinou o autor: a compreensão da necessidade histórica leva à transposição das situações limites que ela impõe.

No final da década de 2010, marcada pelo ascenso de governos antidemocráticos de inspiração fascista em nossa América, se faz cada vez mais necessário, não só revisitar a obra freireana, como atualizá-la como ferramenta de combate aos desvios que tendem a sacrificar os direitos humanos, em detrimento da crescente acumulação de capital. Se, em uma perspectiva gramsciana, as instituições devem abrir brechas na estrutura hegemônica para transformar a realidade que desumaniza, compreendemos que esta metodologia de ensino-aprendizagem-pesquisa contribui para tal objetivo. Tanto a educação quanto a pesquisa podem ser alicerces que concorrem para construir relações sociais necessárias à concretização dos objetivos de retomada democrática com justiça social em nossas sociedades. 


\section{REFERÊNCIAS}

1. ADAMS, Telmo; STRECK, Danilo R.; MORETTI, Cheron Z. (Orgs.). Educação-pesquisa: mediações para a transformação social. Curitiba: APPRIS Editora, 2017.

2. FREIRE, Paulo. Educação como prática da liberdade. 6ª . ed. Rio de Janeiro: Paz e Terra, 1976.

3. FREIRE, Paulo. Ação Cultural para a liberdade e outros escritos. 5a. Ed. Rio de Janeiro: Paz e Terra, 1981.

4. FREIRE, Paulo; GUIMARÃES, Sérgio. Sobre educação: diálogos. $2^{\mathrm{a}}$ Ed. Rio de Janeiro: Paz e Terra, 1982.

5. FREIRE, Paulo. Pedagogia da esperança: um reencontro com a pedagogia do oprimido. $13^{a}$ Ed. Rio de Janeiro: Paz e Terra, 1992.

6. FREIRE, Paulo. Pedagogia do Oprimido. 50ª Ed. Rio de Janeiro: Paz e Terra, 2011.

7. GIROUX, Henry. Cruzando límites. Trabajadores culturales y políticas educativas. Barcelona: Paidós, 1997.

8. ORTEGA VALENCIA, Piedad. La Educación Popular y su re-significación en la Pedagogía Crítica. In: GUELMAN, Anahí, CABALUZ, Fabián, SALAZAR, Mónica (Coords.). Educación popular y pedagogías críticas en América Latina y Caribe. Corrientes emancipatorias para la educación pública del Siglo XXI. Buenos Aires: CLACSO, 2018 (Colección Grupos de Trabajo). p. 117-140.

9. RODRÍGUEZ, Lidia M. La elección categorial: alternativas y educación popular. In: RODRÍGUEZ, Lidia M. (Dirección). Educación Popular en la historia reciente en Argentina y América Latina. Aportes para balance y prospectiva. $1^{\text {a }}$. ed. Buenos Aires: APPEAL, 2013. p. 25-40.

10. STRECK, D., e ADAMS, T. (2019). Latin American perspectives on participatory methodologies in educational research. In: Oxford Research Encyclopedia of Education. Oxford University Press. [Education, Change, and Development. 18 p.]. Disponível em: https://oxfordre.com/education/view/10.1093/acrefore/9780190264093.001.0001/acrefore9780190264093-e-509. Acesso: 14 dez. 2019.

11. TORRES CARRILLO, Alfonso. Por una investigación desde el margen. TORRES, Alfonso; JIMÉNEZ B., Absalón (Orgs.). La práctica investigativa en ciencias sociales. 1ª. reimp. Bogotá: Fondo Editorial Universidad Pedagógica Nacional, 2006. p. 61-79. 


\section{Telmo Adams}

Professor Pesquisador, Programa de Pós-Graduação em Educação.

\section{Camile Pegoraro}

PPGEducação, Unisinos.

\section{Como citar este documento:}

ADAMS, Telmo; PEGORARO, Camile. Educação e pesquisa: contribuições teórico-metodológicas de Freire à pedagogia crítica na América Latina. Reflexão e Ação, Santa Cruz do Sul, v. 28, n. 3, p. 35-49, ago. 2020. ISSN 1982-9949. Disponível em: <https://online.unisc.br/seer/index.php/reflex/article/view/14677>. Acesso em: doi:https://doi.org/10.17058/rea.v28i3.14677. 